\title{
UZROCI, POSLJEDICE I PRAĆENJE INTRAKRANIJALNE HIPERTENZIJE
}

\author{
CAUSES, CONSEQUENCES AND MONITORING INTRACRANIAL HYPERTENSION
}

\author{
Vesna Ivanišević, Mišo Miškić, Peđa Kovačević, Danica Momčićević, Saša Dragić
}

\begin{abstract}
Sažetak: Intrakranijalna hipertenzija je najčešći patofiziološki mehanizam u neuropatologiji. Međutim, činjenica da ne postoji opšta zakonitost između skoka intrakranijalnog pritiska i nastanka neurološkog oštećenja čini ovaj patofiziološki entitet uvijek aktuelnim. Odnos između morfoloških endokranijalnih patoloških entiteta sa CT verifikacijom, kao uzroka intrakranijalne hipertenzije koje smo istražili na kliničkom materijalu slaže se s podacima iz literature, uz to da su se nominalne vrijednosti u pogledu zastupljenosti intrakranijalnih ekspanzivnih procesa tumorske etiologije približile intrakranijalnim patološkim entitetima traumatske etiologije. Značaj kliničkog, neinvazivnog $i$ invazivnog praćenja intrakranijalne hipertenzije je pomoć u prepoznavanju momenta nakon koga promjene uzrokovane negativnim djelovanjem intrakranijalne hipertenzije postaju ireverzibilne.
\end{abstract}

Ključne riječi: intrakranijalna hipertenzija, Monro-Kelijeva doktrina, neurološko oštećenje.

\section{UVOD}

Pod intrakranijalnim pritiskom podrazumijeva se pritisak unutar lobanje, u samom moždanom tkivu i cerebrospinalnom likvoru. Njegove normalne vrijednosti u ležećem položaju i mirovanju su između 7 i $15 \mathrm{~mm} \mathrm{Hg}$, dok u stojećem položaju on postaje negativan i iznosi prosječno $-10 \mathrm{mmHg}$ [1].

Izraženo u procentima intrakranijalni prostor kod odraslih osoba sastoji se od $87 \%$ moždanog tkiva, $9 \%$ cerebrospinalnog likvora i $4 \%$ krvi [2]. Radi lakšeg teoretskog razmatranja patofizioloških mehanizama intrakranijalne hipertenzije, prema Monro-Kelijevoj doktrini intrakranijalni prostor je podijeljen u četiri odjeljka: ekstracelularni prostor, intracelularni prostor, cerebrospinalni likvor i krv. Kod aproksimativnih $1500 \mathrm{ml}$ zapremine intrakranijalnog prostora, $1100 \mathrm{ml}$ je zapremiina intracerebralnog prostora, $200 \mathrm{ml}$ je zapremina ekstracerebralnog prostora, $140 \mathrm{ml}$ zapremina cerebrospinalnog likvora i $60 \mathrm{ml}$ zapremina krvi. Prema Monro-Kelijevoj doktrini povećanje zapremine u jednom od odjeljaka praćeno je recipročnom promjenom u nekom drugom odjeljku.

Oštećenje mozga bilo koje etiologije dovodi do pojave intrakranijalne hipertenzije, koja je prema visini intrakranijalnog pritiska podijeljena u tri grupe i terminološki označena kao:
1.Blaga intrakranijalna hipertenzija $(15-25 \mathrm{~mm} \mathrm{Hg})$

2.Srednje teška intrakranijalna hipertenzija(25-40 $\mathrm{mm} \mathrm{Hg}$ )

3.Teška intrakranijalna hipertenzija $(>40 \mathrm{~mm} \mathrm{Hg})$

Većina kliničara danas smatra štetnim sve skokove intrakranijalnog pritiska iznad raspona vrijednosti koji se kreće između 15 i $20 \mathrm{mmHg}$. Međutim, ono sa čim se kliničari susereću u svakodnevnoj praksi je činjenica da ne postoji opšta zakonitost između skoka intrakranijalnog pritiska i nastanka neurološkog oštećenja [3]. Na primjer, kašalj ili kihanje mogu izazvati skok intrakranijalnog pritiska za preko 50 $\mathrm{mmHg}$, ali uglavnom ne dovode do neurološkog oštećenja. U eksperimentalnim uslovima, ubrizgavanjem fiziološkog rastvora u komorni sistem intrakranijalni pritisak je podizan na vrijednosti preko $100 \mathrm{mmHg}$ bez znakova nurološkog oštećenja. Sa druge strane, određena kraniocerebralna povreda može biti praćena umjerenim porastom intrakranijalnog pritiska i završiti letalno.

Povećanje intrakranijalnog pritiska usljed patološkog procesa mozak može kompenzovati do određene granice. Prema Mono-Kelijevoj doktrini sposobnost intrakranijalnih odjeljaka da se prilagode zapreminskim promjenama bez povećanja pritiska naziva se puferski kapacitet. Puferski kapacitet 
uključuje brze i dugotrajne mehanizme akomodacije na patološki supstrat. Brzi mehanizam podrazumijeva premještanje krvi i cerebrospinalnog likvora između odjeljaka lobanjske šupljine, dok dugotrajni mehanizam podrazumijeva promjenu zapremine ekstracelularnog prostora što utiče na volumen moždanog parenhima koji se može smanjiti za 50\%. Istiskivanje vode iz intersticijalnog prostora kao odgovor na cerebralnu kompresiju opisuje se kao ponašanje slično sunđeru. Kada ipak dođe do povećanja intrakranijalnog pritiska smanjuje se perfuzioni pritisak u mozgu što čini uvod u lanačanu reakciju koja može dovesti do moždane ishemije. Drugi mehanizam, kojim povišen intrakranijalni pritisak oštećuje mozak je pomjeranje moždanih struktura između anatomskih granica usljed kojih dolazi do hernijacija moždanog tkiva. Unutar određenih vremenskih granica taj proces je reverzibilan $\mathrm{i}$ to je osnova za konzervativnu ili hiruršku terapiju intrakranijalne hipertenzije i očuvanje integriteta centralnog nervnog sistema.

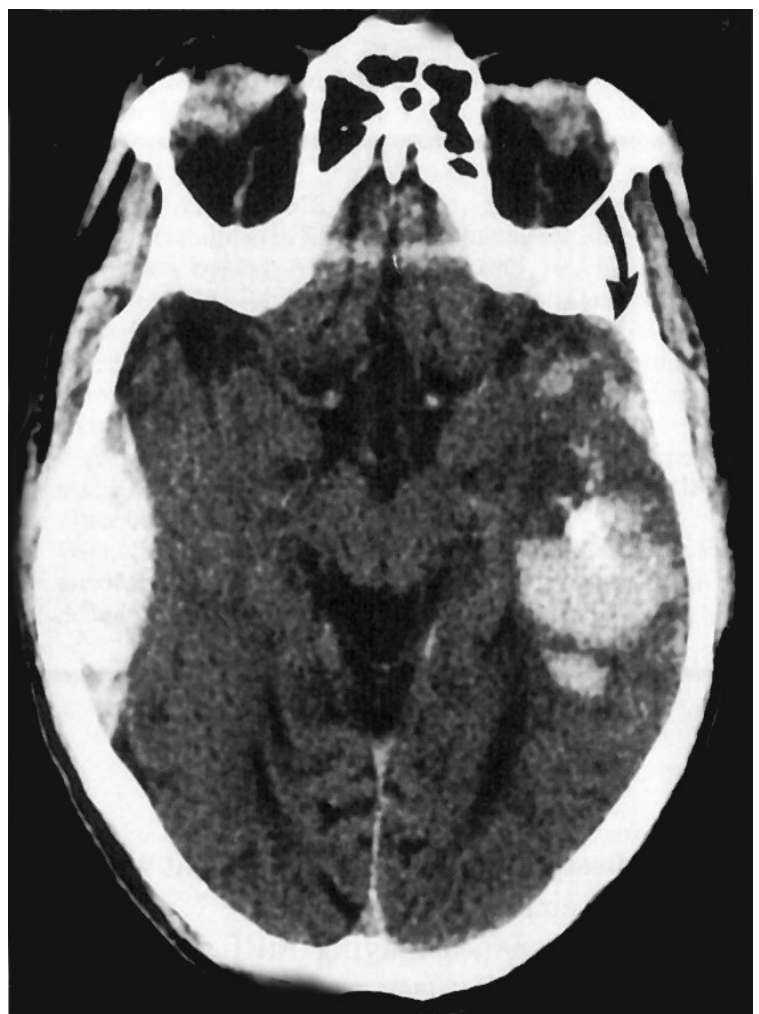

Slika 1. Intracerebralni epiduralni hematom

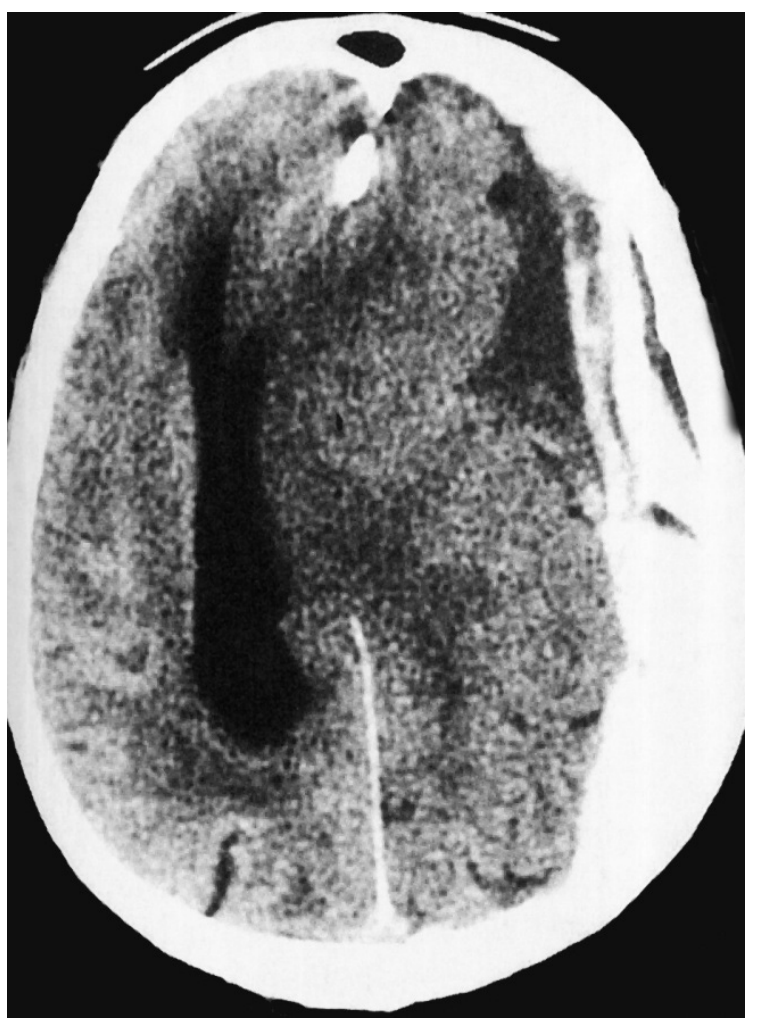

Slika 2. Uklještenje mozga

\section{MATERIJAL I METODE}

Naš materijal činili su ispitanici sa radiološki (CT) verifikovanim morfološkim ekspanzivnim procesom, a koji su liječeni u Službi za neurohirurgiju tokom 2016. godine i to njih ukupno 343 ispitanika. Metodom grafičkog prikaza pokazali smo procentualnu zastupljenost određenih grupa patomorfoloških entiteta koji su uzrokovali intrakranijalnu hipertenziju a koja kod svih ispitanika ima radiološku (CT) verifikaciju. Najčešće patološke entitete koji dovode do intrakranijalne hipertenzije, a liječeni su u Službi za neurohirurgiju grupisali smo u slijedeće tri skupine:

1. Traumatske ekspanzivne intrakranijalne procese

2. Intrakranijalne ekspanzivne procese tumorske etiologije

3. Spontane intrakranijalne hemoragije (najčešće subarahnioidalne hemoragije).

Metodom grafičkog prikaza pokazali smo procentualnu zastupljenost ovih grupa patoloških entiteta kao uzroka intrakranijalne hipertenzije koja kod svih ispitanika ima radiološku (CT) verifikaciju. 


\section{REZULTATI}

Ukupan uzorak je brojao 343 ispitanika sa CT verifikovanim uzrokom intrakranijalne hipertenzije. Rezultati su pokazali da se kao uzrok intrakranijalne hipertenzije najčešće zastupljeni intrakranijalni traumatrski ekspanzivni procesi sa 144 (40.5\%) (Grafik 1). Na drugom mjestu po zastupljenosti su intrakranijalni ekspanzivni procesi traumatske etiologije i to kod 135 ispitanika (40.3\%) (Grafik 2), dok su spontane intrakranijalne hemoragije kao uzrok povišenog intrakranijalnog pritiska verifikovane u 64 slučaja (19.2\%) (Grafik 3).

Procentualni udio kraniocerebralne traume $u$ ukupnom broju patoloških CT nalaza

Percentage share of craniocerebral trauma in the total number of pathologic CT findings

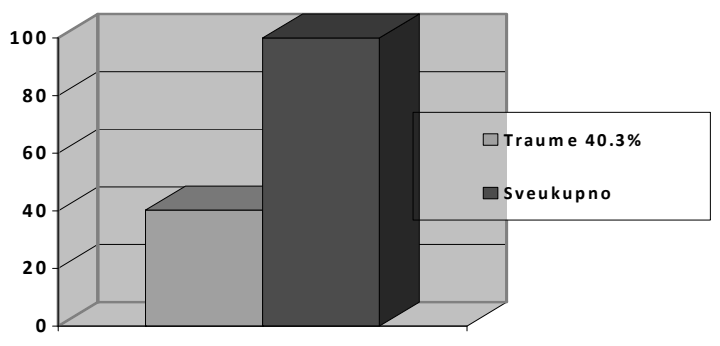

Grafik 1 .

Procentualni udio endokranijalnih tumora $\mathrm{u}$ ukupnom broju patoloških CT nalaza

Percentage share endocranial tumors in the total number of pathologic CT findings

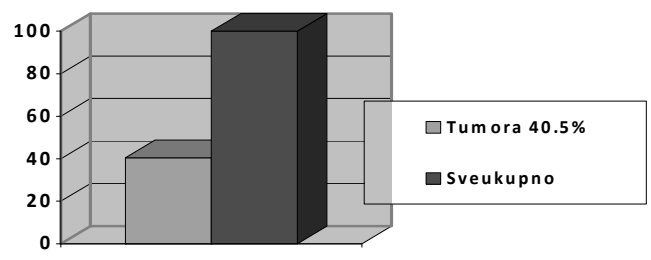

Grafik 2.

Procentualni udio spontanih hemoragija $u$ ukupnom broju patoloških CT nalaza

Percentage share of spontaneous hemorrhage in the total number of pathologic CT findings

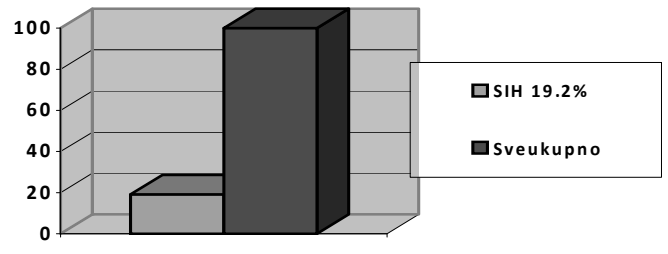

Grafik 3.

\section{DISKUSIJA}

Rezultati našeg istraživanja pokazali su da je u ispitivanom uzorku najčešći uzrok intrakranijalne hipertenzije traumatsko moždano oštećenje što se slaže sa podacima iz literature [4]. Treba napomenuti da su navedeni rezultati odraz stanja pacijenata liječenih u Službi za neurohirurgiju Univerzitetskog kliničkog centra u Banjoj Luci.

Osim činjenice da je teška kraniocerebralna trauma najčešći uzrok povećanja intrakranijalnog pritiska u slučaju moždanog oštećenja uzrokovanog kraniocerebralnom traumom stepen intrakranijalne hipertenzije je u direktnoj vezi sa lošim ishodom. Među bolesnicima sa nekontrolisanom intrakranijalnom hipertenzijom uzrokovanom teškom kraniocerebralnom traumom smrtni ishod je 92\%. I pored terapije (konzervativna ili hirurška) $50 \%$ bolesnika sa teškom kraniocerebralnom povredom umire zbog intrakranijalne hipertenzije.

Kod intrakranijalnih tumora generalno, njihovim uvećanjem dolazi do pomjeranja cerebrospinalnog likvora i krvi, a intrakranijalni pritisak ostaje normalan sve do kasnog stadija njihovog razvoja dok $\mathrm{u}$ terminalnom stadijumu malo povećanje volumena tumorskog ekspanzivnog procesa dovodi do stvaranja visokog talasa intrakranijalnog pritiska. Porast intrakranijalnog pritiska $u$ prisustvu unilateralnog ekspanzivnog procsa, praćen je višim morbiditetom i mortalitetom. Unilateralne lezije izazivaju gradijent pritiska između odjeljaka lobanjske šupljine, pomijeranje intrakranijalnih struktura i na kraju kompresiju moždanog stabla [5]. Ekspanzije u frontalnim režnjevima dovode do značajnog porasta intrakranijalnog pritiska prije nego što dođe do manifestnih kliničkih znakova pritiska na moždano stablo. Nasuprot ovom lezije temporalnog režnja mogu dovesti do kompresije moždanog stabla prije nego što dođe do značajnog porasta intrakranijalnog pritiska. Ruptura 
intrakranijalne aneurizme dovodi do naglog prolaznog povećanja intrakranijalnog pritiska koji može ići do nivoa krvnog pritiska.

Kao što je ranije navedeno, kliničko stanje bolesnika ponekad ne korelira sa visinom intrakranijalnog pritiska. Pod izvjesnim okolnostima intrakranijalni pritisak može dostići i $50 \mathrm{mmHg}$ a da pri tome izostane pojava njegovih kliničkih znakova. Ovakva stanja najčešće se javljaju kod difuznih oštećenja mozga koja ne dovode do morfoloških oštećenja i uklještenja.

Klinički simptomi povišenog intrakranijalnog pritiska su glavobolja, povraćanje i edem papile očnog živca. Glavobolja i povraćanje su uzrokovani moždanim pomjeranjem koje dovodi do trakcije krvnih sudova, dure i ostlih senzitivnih struktura, a edem papile očnog živca je direktni znak povišenog intrakranijalnog pritiska. Glavobllja udružena sa povišenim intrakranijalnim pritiskom najjača je u jutarnjim satima dok se tokom dana smanjuje. Povraćanje je obično najraniji simptom kod djece i nije udruženo sa osjećajem mučnine, a dovodi do naglog prestanka glavobolje. Zastojna papila je jedan od najpouzdanijih znakova povišenog intrakranijalnog pritiska ali se ipak kod velikog broja pacijenata sa intrakranijalnom hipertenzijom ne razvije Bitno je istaći da mnogi patološki procesi, počevši od retrobulbarnog tumora orbite te granulomatoznih zapaljenja i cističnih lezija vagine optičkog živca pa preko okularne hipotonije i venske staze dovode do edema papile uz potpuno normalne vrijednosti intrakranijalnog pritiska. Kao što je već pomenuto, kliničko stanje bolesnika ponekad ne korelira sa visinom intrakranijalnog pritiska [6].

Iz svega naprijed navedenog jasno je da udruženost intrakranijalne hipertenzije sa poremećajem cerebralne funkcije, osim poremećaja moždane perfuzije i deformacije anatomske konfiguracije mozga uslovljava još niz veoma složenih patofizioloških mehanizama. Nepravilnost u pojavljivanju kliničkih simptoma i znakova dodatno usložnjava procjenu kliničara o stepenu moždanog oštećenja usljed negativnog djelovanja povišenog intrakranijalnog pritiska.

Neinvazivni monitoring moguć je jedino kod novorođenčadi preko fontanele, dok se kod odraslih koristi mjerenje intrakranijalnog pritiska burr-hole metodom kroz lobanju. Instrumenti invazivnog monitoringa mogu biti ubačeni $u$ jedan od slijedećih intrakranijalnih odjeljaka:

1. Lateralnu komoru (sa vrhom katetera u blizini Monroovog otvora) - ovaj metod omogućava najpreciznije mjerenje, istovremeno je omogućena evakuacija cerebrospinalnog likvora kao metoda za snižavanje povišenog intrakranijalnog pritiska.

2. Subduralno-subarahnoidalni prostor - manje precizno od prethodne metode bez mogućnosti terapijskog rasterećenja.

3. Moždani parenhim.

4. Epiduralni prostor - koji je sigurnija alternativa $u$ pogledu rizika od infekcije ali je i tačnost mjerenja manja.

Danas se u praksi za ekzaktno mjerenje intrakranijalnog pritiska najčešće koristi intraventrikularni kateter. Ustvari, radi se o eksternom sistemu za drenažu likvora na koji je dodan trandjuser koji električne impulse prtvara $\mathrm{u}$ brojke, a može biti postavljen intra ili ekstrakranijalno. Ograničenje i oprez u postavljanju indikacija za primjenu invazivnog intrakranijalnog monitoringa predstavljaju direktne komplikacije: krvarenje i infekcija. Prema podacima iz literature učestalost infekcije kreće se od $0-22 \%$ a tipovi infekcije koje se javljaju, uključuju infekciju kože, osteomijelitis, meningitis, moždani absces i ventrikulitis. Na mogućnost infekcije posebno treba misliti kod pacijenata starije životne dobi, kod pacijenata koji su imali ranije neurohirurške procedure, kod prisustva intracerebralnih hematoma kao i od otvorenih kraniocerebralnih povreda. Trajanje monitoringa ima veliki značaj u nastajanju infekcija, jer se mali broj infekcija javlja u prva tri dana ali njihov broj rapidno raste nakon 5 dana. Krvarenje nastaje u 1-2 \% slučajeva, a vezano je za invazinu prirodu instrumenata.

\section{ZAKLJUČAK}

- Ne postoji opšta zakonitost između skoka intrakranijalnog pritiska i nastanka neurološkog oštećenja.

- Specifičnosti patofiziološkog djelovanja i kliničke ekspresije intrakranijalne hipertenzije usko su povezane s njenom etiologijom.

- Zbog čenjenice da odnos između visine intrakranijalne hipertenzije i cerebralnog oštećenja nije jednoznačan, već zavisi od niza 
veoma složenih patofizioloških procesa, u određenom broju slučajeva potrebno je njeno egzaktno mjerenje (invazivni intraktranijalni monitoring).

\section{LITERATURA}

1. Sauaia A, Moore FA, Moore EE, Moser KS, Brennan R, Read RA el al. Epidemiology of trauma deaths: a reassessment. J.Trauma 1995;38:185-93.

2. Marshall LF. Head Injury: recent past, present, and future. Neurosurgery 2000;47:546-61.

3. Duff D. Altered states of conciousness, theories of recovery and assessment, following a severe traumatic brain injury. Axone 2003;2-18.

Vesna Ivanišević

Služba za neurohirurgiju

Univerzitetski klinički centar Republike Srpske

Telefon: +38765510779

E-mail:vesna.ivanisevic@kc-bl.com
4. Kraus JF, Mac Arthur DI, Silvermen TA. Jayaraman N. Epidemiology of brain injury. In: Narayan RK, Wilberger Jr JE, Povlishockeditors, Neurotrauma, New York: McGraw-Hill, 1996:13-30.

5. G. Tindal. The practice of neurosurgery1996;1426510.

6. Brauns JR Hauser WA. The epidemiology of traumatic brain injury, Epilepsia 2003;44:2-10.

7. Walsh KB, Woo D, Sekar P, Osborne J, Moomaw CJ, Langefeld CD, Adeoye O. Untreated Hypertension: A Powerful Risk Factor for Lobar and Nonlobar Intracerebral Hemorrhage in Whites, Blacks, and Hispanics. Circulation 2016;134(19):1444-52. 